\title{
Identifying Lychee (Litchi chinensis Sonn.) Cultivars and their Genetic Relationships Using Intersimple Sequence Repeat (ISSR) Markers
}

\author{
Chemda Degani, Jiusheng Deng, ${ }^{1}$ Avigdor Beiles, ${ }^{2}$ Ruth El-Batsri, Moshe Goren, and Shmuel Gazit ${ }^{3}$ \\ Institute of Horticulture, Agricultural Research Organization, The Volcani Center, Bet-Dagan, Israel
}

\begin{abstract}
ADDiTIONAL INDEX wORDS. anchored microsatellites, polymorphism, DNA fingerprinting, germplasm
Absract. There is widespread confusion and uncertainty concerning the identity of lychee cultivars: the same cultivar may be known under different names and different cultivars may appear under the same name. In the present study, the potential of intersimple sequence repeat (ISSR) for the identification of 66 lychee cultivars and accessions and a determination of their genetic relationships was evaluated, using 32 primers containing different simple sequence repeat motifs. Of the 194 bands produced, 124 (64\%) were polymorphic. A set of six ISSR primers was sufficient to distinguish all cultivars and accessions. Thus, cultivars which are morphologically very similar and have identical isozyme profiles can be distinguished by ISSR analysis. However, seven pairs of accessions, each considered to be the same cultivar, were found to be identical by ISSR analysis. Nei and Li band-sharing distances and Nei genetic distances were calculated among the cultivars and two similarity dendrograms were generated using the neighbor-joining algorithm. Results showed that the ISSR technique is a valuable tool for identification of lychee cultivars and analysis of their genetic relationships.
\end{abstract}

Lychee (Litchi chinensis Sonn.) originated in China, where it has been grown for $>3000$ years (Maity and Mitra, 1990). It has been introduced to other tropical and warm subtropical regions only in the last two centuries (Knight, 1980). In China, the lychee is known as the king of fruit, for its excellent taste and nutritional value (Zhang et al., 1997). The red, attractive, small fruit is borne in bunches. The fresh fruit is quite perishable, encouraging preservation by drying. Dried lychee has been erroneously called litchi nut, creating confusion about the nature of this delicious fruit (Morton, 1987).

Selection of superior lychee seedlings began $>1000$ years ago. Thirty-two lychee cultivars were already described in a compendium on lychee published in 1059 in Fujian, China (Groff, 1921). Today there is widespread confusion over the identities of lychee cultivars (Batten, 1984; Cavaletto, 1980; Galan-Sauco and Menini, 1989; Goren et al., 2001; Menzel and Simpson, 1990; Zee et al., 1998). The confusion originates in China. In different localities, the same cultivar may have different names and different cultivars may have the same name (Pomology Research Institute, 1985, 1990; Zhang et al. 1997). A part of this confusion is the result of simple misidentification. For example, 'Nuo Mi Ci' is a famous Chinese cultivar, with several distinct characteristics that make it easy to identify; nevertheless, in some localities this name is used for other cultivars that do not resemble the genuine 'Nuo Mi Ci' (Gazit and Goren, 1997). A more common phenomenon is that of individual cultivars having partially or totally different names in different localities. The different Chinese dialects also constitute a major source of confusion, especially for people who do not read Chinese. Frequently, the same cultivar has different names in different dialects. To solve this problem, recent publications have adopted the convention of using the official

Received for publication 30 Dec. 2002. Accepted for publication 7 July 2003. Contribution from the Agricultural Research Organization, The Volcani Center, Bet-Dagan Israel, no. 05, 2002 series.

${ }^{1}$ Guangxi Polytech Institute, Mingyuang, Nanning, Guangxi, China.

2Institute of Evolution, Univ. of Haifa, Haifa 31905, Israel.

${ }^{3}$ The Kennedy-Leigh Centre for Horticultural Research, The Hebrew University of Jerusalem, Rehovot 76100, Israel.
Mandarin dialect for lychee cultivar names. Another source of confusion - which is very difficult to resolve - is the erroneous identification of seedlings, which closely resemble a certain cultivar, as the genuine cultivar. Thus, some cultivars may consist of a mixture of genotypes (Winston and O'Farrell, 1993). In the course of lychee's dissemination to other countries, the confusion in cultivar identities increased. Many introduced cultivars lost their identity entirely or were misidentified. Renaming in local languages also complicated the situation. A good example of the confusion, that has occurred with the identity of lychee cultivars outside of China, is the story of 'Kwai Mi' in Hawaii. A lychee accession under the name of the famous Chinese cultivar 'Kwai Mi' (in Cantonese, or 'Gui Wei' in Mandarin) was introduced to Hawaii from China in 1873. It was the main lychee cultivar in Hawaii for many years. Two additional names - 'Charlie Tong' and 'Annie May Wong' - were coined in Hawaii for the same cultivar. However, the morphological characteristics of the cultivars did not match those of the Chinese cultivar of the same name. After 'Mauritius' was introduced from South Africa it became obvious that it looked identical to the Hawaiian 'Kwai Mi', and that the name under which the accession had been introduced was completely erroneous (Hamilton and Yee, 1970; Storey, 1973). It is now known that 'Mauritius' is synonymous with the Chinese cultivar 'Da Zao' ('Tai So' in Cantonese; Batten, 1984).

Traditionally, cultivar identification of lychee in China has been based on morphological traits: vegetative, floral and fruit characteristics and the harvest season (Batten, 1984). The usefulness of this approach is limited in that the expression of morphological features is often affected by the environment (Nielsen, 1985). Furthermore, it is often very difficult to distinguish among closely related cultivars by morphological traits alone. Recently, 12 polymorphic enzyme systems were resolved for identifying lychee cultivars (Aradhya et al., 1995; Degani et al., 1995). However, the main limitation of isozyme analysis is the small number of loci that can be examined. Hence, cultivars that are closely related often have identical isozyme patterns. This limitation is overcome by the utilization of DNA markers.

In this study we used intersimple sequence repeat (ISSR) 
Table 1. Lychee cultivars and accessions used in this study along with their source of introduction and place of origin.

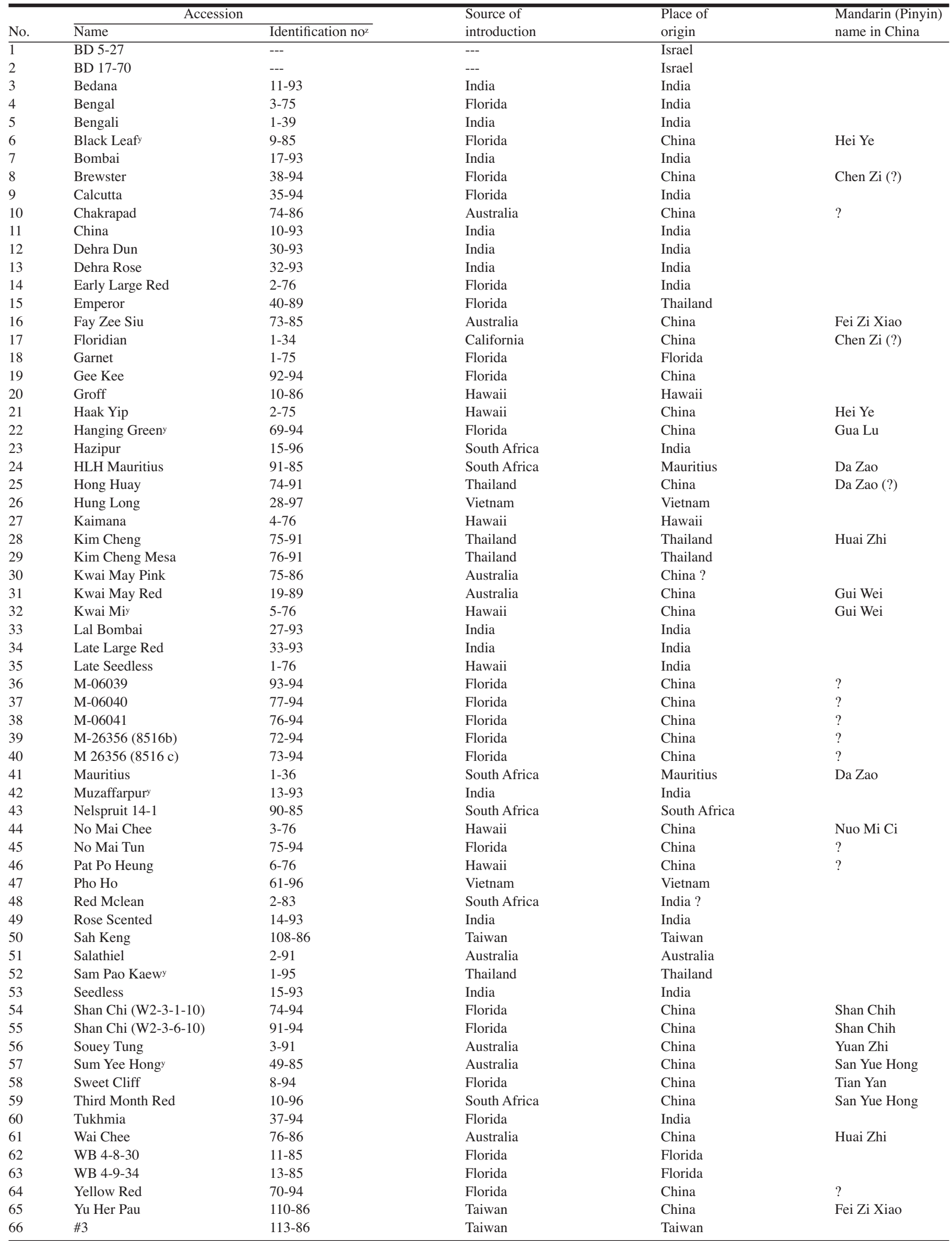

${ }^{2}$ The last two digits indicate the year of introduction (20 $2{ }^{\text {th }}$ century).

yErroneous name. 
markers which are generated by microsatellite-repeat-anchored primers amplifying genomic segments between adjacent SSR loci (Zietkiewicz et al., 1994). These primers target microsatellites that are abundant throughout the plant genome (Wang et al., 1994), making prior knowledge of the target sequences unnecessary. These primers offer great potential for fingerprinting compared to other arbitrary primers, since they simultaneously target multiple genomic loci (Zietkiewicz et al., 1994). Polymorphisms occur whenever one genome lacks the repeated sequence or has a deletion or insertion that modifies the distance between repeats. The ISSR method can differentiate between closely related individuals (Fang and Roose, 1997; Moreno et al., 1998; Zietkiewicz et al., 1994). ISSR markers have been used for cultivar identification and for genetic relationship studies in various plant species (Ajibade et al., 2000; Blair et al., 1999; Fang and Roose, 1997; Fang et al., 1998; Gilbert et al., 1999; Goulao et al., 2001; Lanham and Brennan, 1998; Martin and Sanchez-Yelamo, 2000; Moreno et al., 1998; Prevost and Wilkinson, 1999).

The objective of this study was to evaluate the utility of ISSR markers for fingerprinting and to study the genetic relationships among 66 lychee cultivars and accessions held in our lychee germplasm repository.

\section{Materials and Methods}

Plant material. Sixty-six lychee accessions in the lychee germplasm collection at the Volcani Center, Bet Dagan, Israel were sampled for DNA extraction and ISSR analysis. Table 1 lists the accessions studied, the source country from where the graftwood was imported and the country of origin.

DNA EXTRaCtion. Young expanding leaves $(\approx 1$ to 3 weeks old, $10 \%$ to $80 \%$ of their final size) were sampled from each of the 66 cultivars. Sampling was carried out within 1 month in the spring. Some complementary sampling was performed during the summer. At least two samples were taken from each tree. About $2 \mathrm{~g}$ of fresh leaflets, without their midvein, were used for DNA extraction. DNA was isolated using the CTAB (cetyltrimethylammonium bromide) procedure of Doyle and Doyle (1990), as modified by Rowland and Nguyen (1993), except that polyethylene glycol precipitation was omitted. DNA concentrations were estimated by agarose gel electrophoresis ( $1 \%$ gel containing $0.5 \mu \mathrm{g} \cdot \mathrm{mL}^{-1}$ ethidium bromide) using known concentrations (15 to $500 \mathrm{ng}$ ) of uncut lambda DNA (Gibco BRL, Gaithersburg, Md.) as standards.

ISSR ANALYSIS. ISSR primers were purchased from the Oligonucleotide Synthesis Laboratory, Nucleic Acid-Protein Service Unit, University of British Columbia (Vancouver, BC, Canada; UBC primer Kit \#9). Each 25- $\mu \mathrm{L}$ amplification reaction consisted of 10 mm Tris- $\mathrm{HCl}(\mathrm{pH} 9.0), 50 \mathrm{~mm} \mathrm{KCl,} 1 \%$ (w/v) Triton X-100, 1\% (w/ v) bovine serum albumin, $2.5 \mathrm{mM} \mathrm{MgCl}_{2}, 200$ $\mu \mathrm{M}$ of each dNTP (Roche Diagnostics $\mathrm{GmbH}$, Mannheim, Germany), 1 M primer, $2 \%$ formamide, 1 unit of Taq polymerase (Promega, Madison, Wis.) supplied in storage buffer A, and $25 \mathrm{ng}$ of template DNA. Amplification was performed in an MJ Research thermal cycler (PTC-100, MJ Research, Watertown, Mass.) using the following program: $4 \mathrm{~min}$ at $94^{\circ} \mathrm{C}$ for 1 cycle, followed by $1 \mathrm{~min}$ at $94^{\circ} \mathrm{C}, 1 \mathrm{~min}$ at $50^{\circ} \mathrm{C}$, and $2 \mathrm{~min}$ at $72{ }^{\circ} \mathrm{C}$ for 44 cycles, and $7 \mathrm{~min}$ at $72^{\circ} \mathrm{C}$ for a final extension. Amplification products were electrophoresed on a $2 \%$ agarose gel containing $0.5 \mu \mathrm{g} \cdot \mathrm{mL}^{-1}$ ethidium bromide, using $0.5 \times$ Tris borate buffer (Sambrook et al., 1989). DNA fragments were photographed using a biological imaging system (Bis 202, DNR Imaging System, Jerusalem, Israel). The molecular weights of the amplification products were estimated using a 100-bp DNA ladder (Gibco BRL, Gaithersburg, Md.).

DATA ANALYSIS. Polymorphic fragments were scored as 1 (present) or 0 (absent). Bands with the same mobility (base pairs) were treated as identical fragments. It is impossible to determine whether a band is homozygous or heterozygous.

On the basis of these ISSR data, Nei and Li (1979) band-sharing distances and Nei genetic distances (Nei, 1972) were calculated using the PHYLIP (version 3.5c) package (Felsenstein, 1993). The difference between the two distance measures is that the first regards only the shared presence of a band, whereas the second gives equal weight to the shared absence and shared presence of a band. In the second distance measure there is some inaccuracy because heterozygosity cannot be determined. However, there is no simple way to estimate this inaccuracy in vegetatively propagated cultivars. The real genetic distance should be between the two distance measures, because only some of the absence bands have the same cause and are evidence for genetic similarity. Two similarity trees (dendrograms) based on those distance matrices were constructed by the neighbor-joining method (Saitou and Nei, 1987), as implemented in the NEIGHBOR procedure of PHYLIP new version 3.6 $\alpha 2$ (Felsenstein, 1985, 2001).

Bootstrap resampling analysis of genetic data was done to test the validity (Felsenstein, 1985) of the similarity dendrogram (presented in the results). The analysis was conducted by the PHYLIP package, version $3.6 \alpha 2$. The following programs were used: SEQBOOT, RESTDIST or GENDIST, NEIGHBOR and CONSENSE. Presence of the topology above $90 \%$ in the 1000 bootstrapping trees was regarded as verification of the observed topology; $80 \%$ to $90 \%$ was regarded as strongly supportive evidence, and $30 \%$ to $80 \%$ as supportive evidence.

\section{Results and Discussion}

ISSR AMPLIFICATION. The amplification of ISSR markers was consistent between repeat PCR runs and across DNA extractions from different leaf samples of the same tree, or from leaves from different trees of the same cultivar.

Representative banding patterns obtained with primer 891 are shown in Fig. 1. From a total of 64 primers screened, 32 that gave

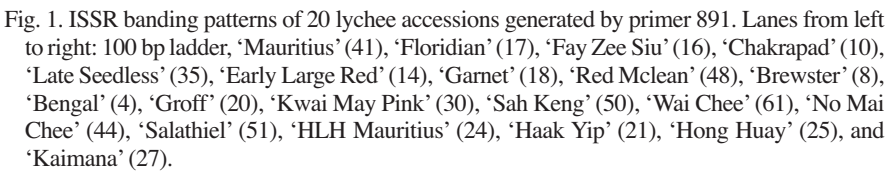
Chee' (44), 'Salathiel' (51), 'HLH Mauritius' (24), 'Haak Yip' (21), 'Hong Huay' (25), and 'Kaimana' (27).

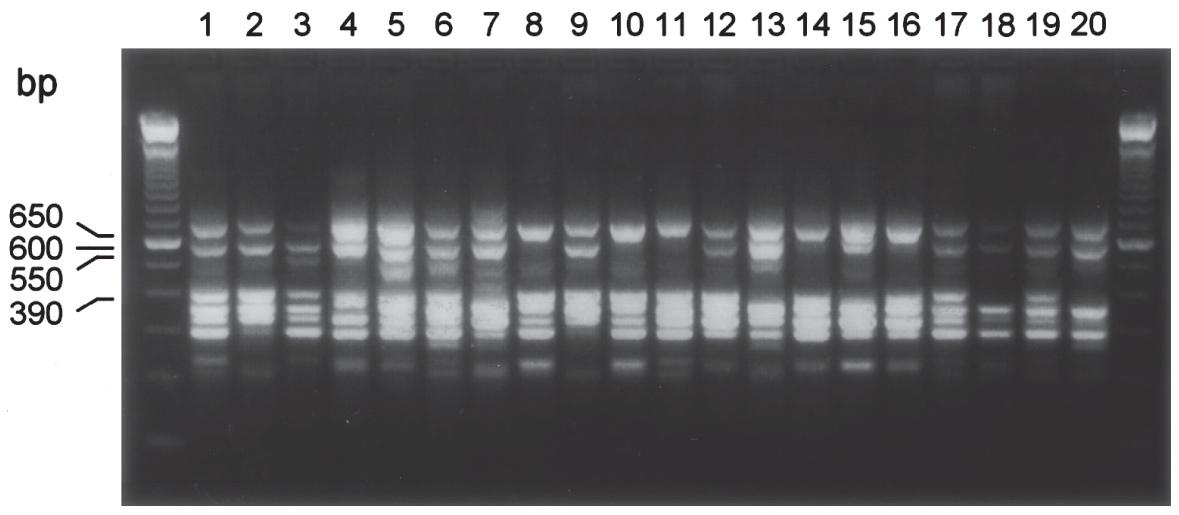


clear reproducible bands were selected (Table 2). Of these, 27 primers (including 23 3'-anchored primers and four 5'-anchored primers) were designed to anneal to dinucleotide repeats, two were designed to anneal to trinucleotide repeats, one was designed to anneal to tetranucleotide repeats and two were designed to anneal to five-nucleotide repeats.

No products were amplified when primers $(\mathrm{AT})_{8} \mathrm{~T},(\mathrm{AT})_{8} \mathrm{C}$, $(\mathrm{AT})_{8} \mathrm{G},(\mathrm{AT})_{8} \mathrm{YA},(\mathrm{AT})_{8} \mathrm{YC},(\mathrm{AT})_{8} \mathrm{YG}$, and $\mathrm{VBV}(\mathrm{AT})_{7}$ were used, although $(\mathrm{AT})_{\mathrm{n}}$ has been reported to be the most abundant microsatellite in plant genomes (Akkaya et al., 1992; Lagercrantz et al., 1993; Wang et al., 1994). In addition, the primers (TA) $\mathrm{A}$,

Table 2. ISSR primers used to fingerprint lychee cultivars: their sequence and the number and size range of polymorphic bands produced by them.

\begin{tabular}{|c|c|c|c|}
\hline \multirow[b]{2}{*}{$\begin{array}{l}\text { Primer } \\
\text { code }^{z}\end{array}$} & \multirow[b]{2}{*}{ Sequence } & \multicolumn{2}{|c|}{ Polymorphic fragments } \\
\hline & & No. & $\begin{array}{c}\text { Size } \\
\text { range } \\
(b p)\end{array}$ \\
\hline \multicolumn{4}{|c|}{ 3'Mono-anchored primers } \\
\hline & $807(\mathrm{AG})_{8} \mathrm{~T}$ & 5 & $300-800$ \\
\hline & $808(\mathrm{AG})_{8} \mathrm{C}$ & 4 & $400-1200$ \\
\hline & $809(\mathrm{AG})_{8} \mathrm{G}$ & 3 & $250-500$ \\
\hline & $810(\mathrm{GA})_{8} \mathrm{~T}$ & 3 & $200-700$ \\
\hline & $817(\mathrm{CA})_{8} \mathrm{~A}$ & 4 & $250-900$ \\
\hline & $818(\mathrm{CA})_{8} \mathrm{G}$ & 1 & 650 \\
\hline & $822(\mathrm{TC})_{8} \mathrm{~A}$ & 5 & $250-950$ \\
\hline & $826(\mathrm{AC})_{8} \mathrm{C}$ & 3 & $250-400$ \\
\hline & $828(\mathrm{TG})_{8} \mathrm{~A}$ & 5 & $380-750$ \\
\hline Polym & c fragments per primer (average) & 3.7 & \\
\hline \multicolumn{4}{|c|}{ 3' Di-anchored primers } \\
\hline & $834(\mathrm{AG})_{8} \mathrm{YT}$ & 4 & $250-750$ \\
\hline & $835(\mathrm{AG})_{8} \mathrm{YC}$ & 2 & $230-350$ \\
\hline & $836(\mathrm{AG})_{8} \mathrm{YA}$ & 4 & $260-370$ \\
\hline & $841(\mathrm{GA})_{8} \mathrm{YC}$ & 7 & $350-550$ \\
\hline & $842(\mathrm{GA})_{8} \mathrm{YG}$ & 6 & $230-750$ \\
\hline & $844(\mathrm{CT})_{8} \mathrm{RC}$ & 3 & $270-550$ \\
\hline & $845(\mathrm{CT})_{8} \mathrm{RG}$ & 4 & $430-750$ \\
\hline & $847(\mathrm{CA})_{8} \mathrm{RC}$ & 7 & $360-970$ \\
\hline & $849(\mathrm{GT})_{8}$ YA & 7 & $280-600$ \\
\hline & $850(\mathrm{GT})_{8} \mathrm{YC}$ & 1 & 700 \\
\hline & $855(\mathrm{AC})_{8} \mathrm{YT}$ & 3 & $280-500$ \\
\hline & $856(\mathrm{AC})_{8} \mathrm{YA}$ & 2 & $310-400$ \\
\hline & $857(\mathrm{AC})_{8} \mathrm{YG}$ & 1 & 360 \\
\hline & $859(\mathrm{TG})_{8} \mathrm{RC}$ & 1 & 450 \\
\hline Polym & c fragments per primer (average) & 3.7 & \\
\hline \multicolumn{4}{|c|}{ Tri-nucleotides } \\
\hline & $864(\mathrm{ATG})_{6}$ & 3 & $340-480$ \\
\hline & $867(\mathrm{GGC})_{6}$ & 2 & $350-520$ \\
\hline \multicolumn{4}{|c|}{ Tetra- and penta-nucleotides } \\
\hline & $873(\mathrm{GACA})_{4}$ & 1 & 280 \\
\hline & $880(\text { GGAGA })_{3}$ & 3 & $280-500$ \\
\hline & $881(\mathrm{GGGTG})_{3}$ & 8 & $280-850$ \\
\hline \multicolumn{4}{|c|}{ 5' Tri-anchored primers } \\
\hline & $888 \mathrm{BDB}(\mathrm{CA})_{7}$ & 6 & $370-650$ \\
\hline & $889 \mathrm{DBD}(\mathrm{AC})_{7}$ & 6 & $360-580$ \\
\hline & $890 \mathrm{VHV}(\mathrm{GT})_{7}$ & 6 & $320-650$ \\
\hline & $891 \mathrm{HVH}(\mathrm{TG})_{7}$ & 4 & $390-600$ \\
\hline Polyms & c fragments per primer (average) & 5.5 & \\
\hline
\end{tabular}

zPrimer numbers follow those in UBC set 9 (no. 801-900).

yR: A,G; Y: C,T; B: C,G,T; D: A,G,T; H: A,C,T; V: A,C,G.
$(\mathrm{TA})_{8} \mathrm{C},(\mathrm{TA})_{8} \mathrm{G},(\mathrm{TA})_{8} \mathrm{RT},(\mathrm{TA})_{8} \mathrm{RC},(\mathrm{TA})_{8} \mathrm{RG}$ and BVB(TA) failed to produce amplification products, indicating that the lychee genome lacks $(\mathrm{AT})_{\mathrm{n}}$ and (TA) $)_{\mathrm{n}}$ motifs or has very few of these microsatellites. It is also possible that lack of amplification products was due to the self-complementary nature of (AT) $)_{n}$ or (TA) primers (Fang and Roose, 1997; Tautz and Renz, 1984).

In total, 194 bands were produced by the 32 primers. Of these, $124(64 \%)$ were polymorphic. The mean polymorphic fragments per primer were 3.7 and 5.5 for 3 ' and 5' -anchored primers, respectively. The primers anchored at the 3 ' end produced patterns which were as clear as those anchored at the 5' end. The combination of six primers, UBC $807,808,845,849,888,891$, allowed us to distinguish among all cultivars and accessions included in this study, except seven pairs which were identical with all 32 primers.

Cultivar identification. Among the accessions analyzed for their ISSR profiles there were several groups, each consisting of accessions that could not be distinguished by either morphological characteristics or isozyme analysis. The ISSR data enabled us to conclude that within these groups certain accessions are identical; or to determine conclusively that they are not. For example, the following eight accessions belong, by their appearance, to the Mauritius group: 'Mauritius' (41), 'Early Large Red' (14), 'HLH Mauritius' (24), 'Hong Huay' (25), the misnamed 'Kwai Mi' (32), the misnamed 'Black Leaf' (6), 'Bengali' (5) and 'Hazipur' (23); all but the latter were isozymically analyzed and found to be identical (Degani, et al., 1995). ISSR analysis showed that only 'Mauritius' and 'HLH Mauritius' are identical, whereas the other accessions differ from this identical pair by two to six mutations (Fig. 2). Indeed, 'HLH Mauritius' and 'Mauritius' were expected to be identical, since both are derived from the original 'Mauritius' tree imported from Mauritius by H.L. Hood (Oppenheimer, 1947; Menzel and Simpson, 1990).

In addition to the identical pair 'HLH Mauritius' and 'Mauritius', we found six more identical pairs. The most interesting and important pair is 'Floridian' (17) and 'Brewster' (8). 'Brewster' was introduced in 1907-08 to the United States from China and became the major lychee cultivar in Florida (Groff, 1948). According to Oppenheimer (1947), 'Floridian' was introduced to Israel in 1934 from the Armstrong nursery in California as a seedling. The great resemblance between these two cultivars prompted us to name this accession 'Floridian', speculating that 'Brewster' was either its generative or vegetative parent. With the ISSR data we can conclude that 'Floridian' was not a seedling but a vegetative 'Brewster' plant. A large amount of research has been carried out with 'Floridian' in Israel; now, the findings obtained and the conclusions reached can be applied to the 'Brewster' in Florida, and apparently also to the synonymous, and important 'Chen $\mathrm{Zi}$ ' in Fujian, China (Groff, 1948). The other five pairs: 'Fay Zee Siu' (16) and 'Yu Her Pau' (65), 'Chakrapad' (10) and 'Emperor' (15), 'Wai Chee' (61) and 'Kim Cheng' (28), 'Haak Yip' (21) and \#3 (66) and the two 'Shan Chi' trees $(54,55)$, have been considered to be identical. Our results confirm these assumptions.

Similar to the situation in the Mauritius group, other accessions with a great resemblance to each other were found to differ to a lesser or greater extent by ISSR analysis (Fig. 2). The misnamed 'Sum Yee Hong' from Australia (58) morphologically resembles the identical pair 'Fay Zee Siu' (16) and 'Yu Her Pau' (65) and has the same isozyme profile (Degani et al, 1995), but ISSR analysis shows that it differs from the pair by five mutations. In fact, Menzel and Simpson (1991) reported confusion with regard to the identity of 'Sum Yee Hong' in Australia. 'Muzaffarpur' (42) and 'Late Large Red' (34) were reported to be the same cultivar (Singh and 
Singh, 1954; Pandey and Sharma, 1989). However, the graftwood of 'Muzaffarpur' that we received from a lychee cultivar plot of an Experimental Station in India produced trees that do not resemble 'Late Large Red'. The ISSR analysis is in line with the morphological observations, showing that these are different cultivars.

'San Yue Hong' (Mandarin name) is the first lychee cultivar to flower and to reach ripeness. The meaning of the name is 'Third Month Red' (59). 'Sum Yee Hong' is the Cantonese version used in Australia (Menzel and Simpson, 1990). Unfortunately, the accession from Australia with this name was found to be misnamed, resembling 'Fay Zee Siu' (16). The 'Third Month Red' introduced from South Africa fits the Chinese description for 'San Yue Hong' (Zhang et al., 1997).

As expected, the use of ISSR markers enabled differentiation among cultivars that could be distinguished by morphological features, but had identical isozyme profiles (Aradhya et al., 1995; Degani et al., 1995). For example, 'Brewster' (8), 'Calcutta' (9) and 'No Mai Tun' (45) have the same isozyme profile, but in our ISSR analysis they were very divergent.

THE SIMILARITY TREE. The dendrogram generated from the ISSR band-sharing distance matrix (Nei and Li, 1979) using the neighbor-joining algorithm (Fig. 2) displays the similarities and divergences among lychee cultivars and accessions. The divergence can be deduced from the length of the horizontal branches. The similarity tree is not exactly a phylogenetic tree, because lychee cultivars evolved by human selection of seedlings, often produced by open pollination (Menzel and Simpson, 1990, 1991), which might cause large genetic divergence between the cultivar and its parents. In this case, the parents cannot be identified in the dendrogram. We chose the neighbor-joining method because it displays the rate of divergence of each cultivar and does not try to estimate chronological time from the average divergence, as is done by UPGMA. Weir (1996) concluded that "Simulations suggest the method (neighbor-joining) to be among the best of the distance matrix methods."

'Third Month Red' (59), which is the wellknown Chinese cultivar 'San Yue Hong', is by far the most divergent accession (Figs. 2 and 3). This supports the suggestion, based on its morphological and phenological characteristics (Huibai Huang, personal communication) that this cultivar should be considered a subspecies of Litchi chinensis Sonn. 'Sam Pao Kaew' (52) is the second most divergent accession. However, its name is erroneous, as its fruit differs significantly from that of the genuine Thai cultivar (Subhadrabandhu, 1990).

For the construction of the similarity tree we selected 'Sam Pao Kaew' (52) to serve as the arbitrary outgroup. It should be mentioned that although we chose a rooted form to present our dendrogram (Fig. 2), the lack of a genuine outgroup leaves it an unrooted tree. We will discuss the groupings from the bottom to the top of Fig. 2. Four main groups can be identified in the similarity tree (Fig. 2).

Group 1 (at the bottom and top of the tree) consists of three accessions $(52,47,46)$ of diverse origin (Thailand, Vietnam and China, respectively).

Group 2 consists of the following three subgroups:

1) Subgroup 2-1 includes five early-ripening accessions. Three of them look the same and all were considered to be identical to the important 'Fay Zee Siu' (16) (Goren et al., 2001). Our analysis revealed that two $(16,65)$ are indeed identical, whereas the third, the misnamed 'Sum Yee Hong' (57), differs by minor genetic changes. The other two accessions $(56,59)$ are known Chinese cultivars, which are morphologically and genetically dissimilar.

2) Subgroup 2-2 includes two accessions $(23,49)$, which resemble the accessions of subgroup 2-3 morphologically, but are at a somewhat greater genetic distance. The third member (1) is a lo-

Fig. 2. A similarity dendrogram of 66 lychee accessions, generated by neighborjoining analysis using Nei and Li (1979) band-sharing distances, based on the ISSR data. The numbers at the forks are bootstrap values, which are the number of times the grouping at the right of that fork was found in 1000 bootstrap resamplings. All values above 300 appear in the dendrogram. The number before each accession name is its number in Table 1 . The numbers appearing at the right-hand margin of the dendrogram indicate the subgroups.

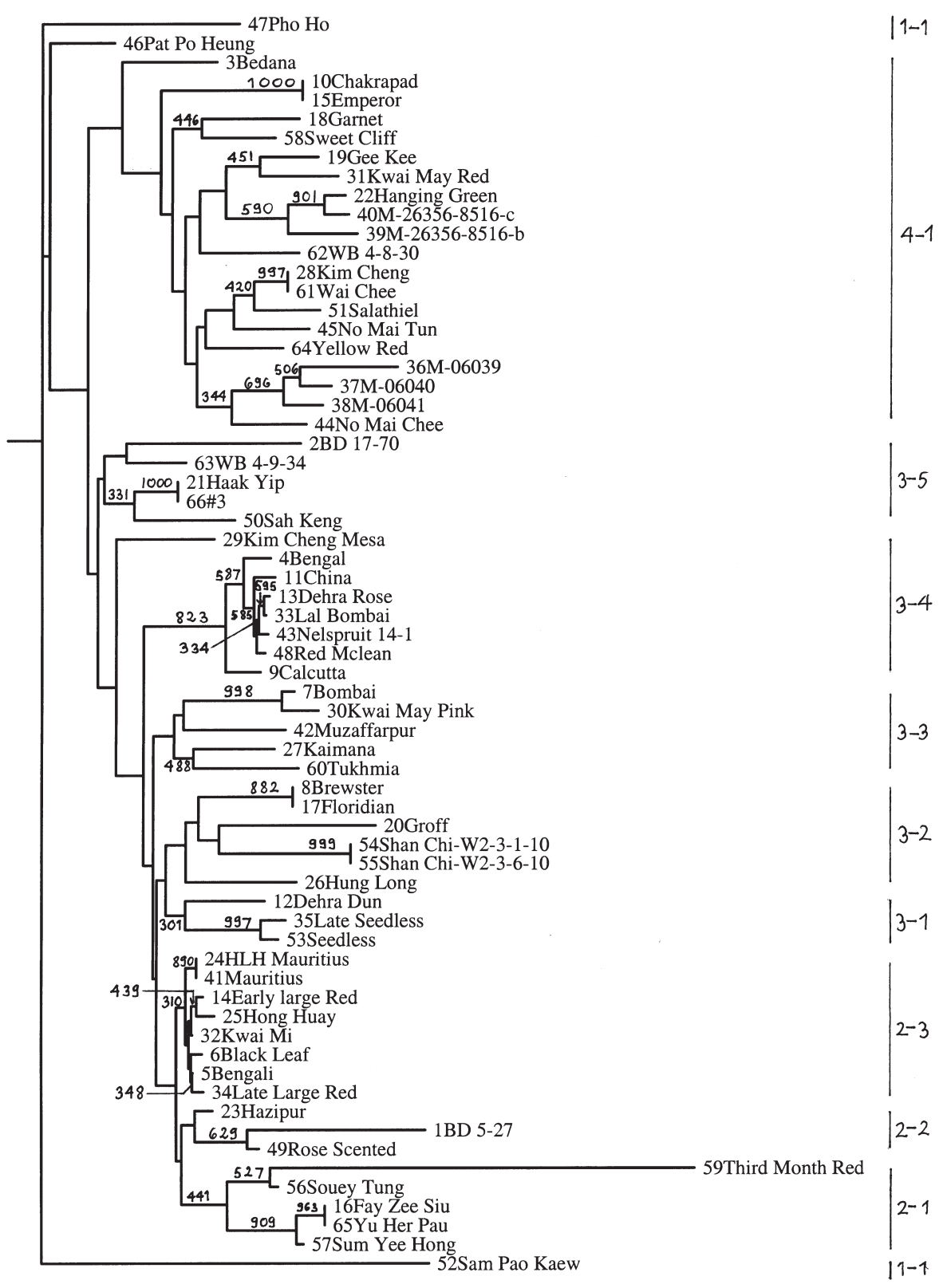


cal selection whose pollen parent is considered to be 'Mauritius' (Goren et al., 2001).

(3) Subgroup 2-3 includes eight accessions, all closely resembling the identical pair: 'Mauritius' (41)-'HLH Mauritius' (24). Among them are five cultivars of Chinese origin, introduced to Israel from various countries: 'Mauritius' (41) (The Botanical Garden, Durban, South Africa), 'HLH Mauritius' (24) (South Africa), 'Hong Huay' (25) (Thailand), the misnamed 'Kwai Mi' (32) (Hawaii) and the misnamed 'Black Leaf' (6) (Florida). The last two were later reidentified as 'Mauritius' (Chapman, 1984; Hamilton and Yee, 1970; R.S. Knight, Jr., personal communication). In addition, this group includes three cultivars of Indian origin: 'Bengali' (5) (West Bengal, India), 'Early Large Red' (14) (Florida) and 'Late Large Red' (34) (India). The subgroup is characterized by the shortest genetic distances, indicating that all are closely related.

Group 3 contains 27 accessions, consisting of one single ac-

Fig. 3. A similarity dendrogram of 66 lychee accessions, generated by neighborjoining analysis using Nei's genetic distances.

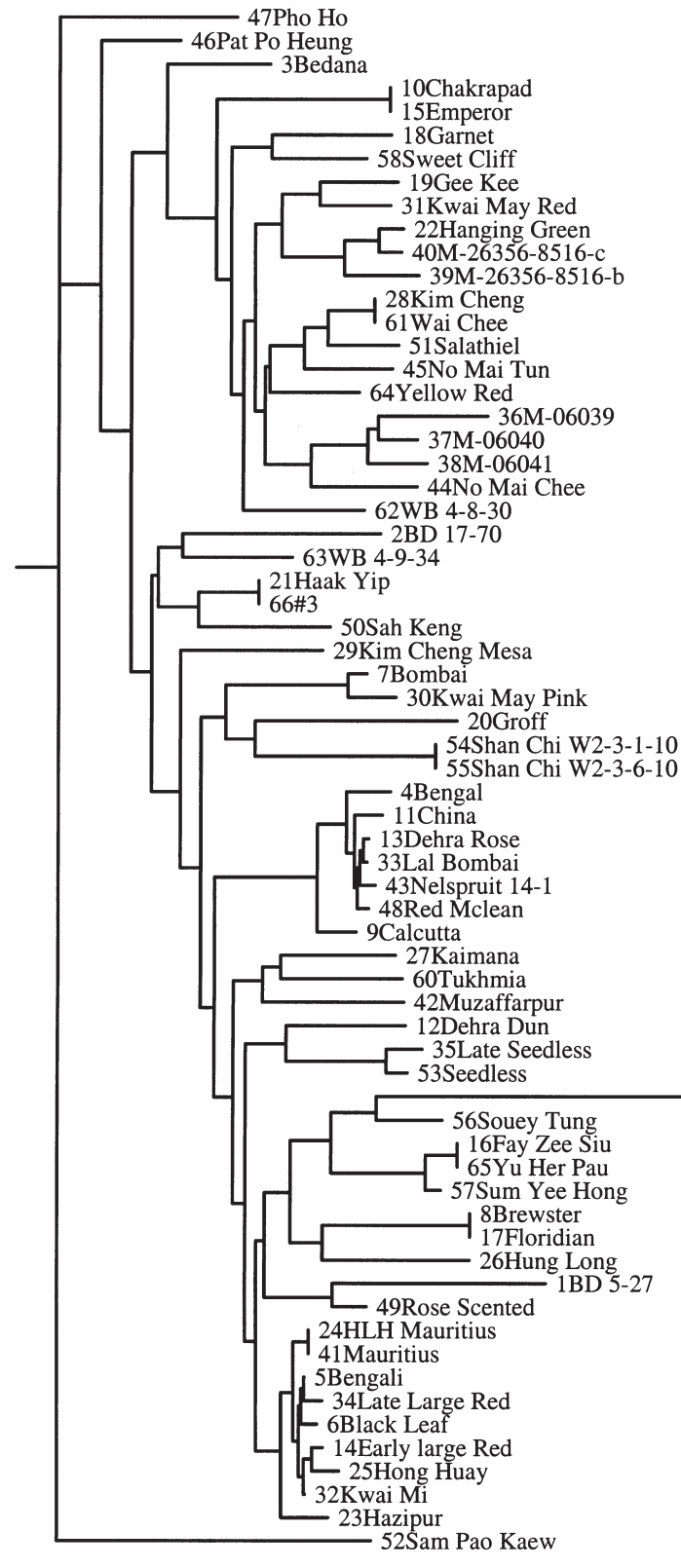
59Third Month Red cession and an additional 26 accessions, which are divided into five subgroups as follows:

1) Subgroup 3-1 includes three Indian accessions; two of them $(35,53)$ are morphologically very similar, whereas the third one (12) is very different.

2) Subgroup 3-2 includes six accessions; four of them are two identical pairs of Chinese origin $(54=55,8=17)$, one is Hawaiian selection (20) and the other is an accession from Vietnam (26), with an unusual vegetative appearance.

3) Subgroup 3-3 includes five accessions that do not have much in common. Three are of Indian origin $(60,42,7)$ : one (42) is apparently misnamed and one (7) has great morphological resemblance to the members of the adjacent subgroup 3-4. The other two are new selections from Hawaii (27) and Australia (30).

4) Subgroup 3-4 includes seven accessions of Indian origin (9, $48,43,33,13,11,4)$, which are morphologically very similar. This subgroup is characterized by very short branches $(13,33$, $43,48)$, demonstrating small genetic distances among the clustered accessions.

5) Subgroup 3-5 includes five accessions of Chinese origin. 'Hak Yip' (21) $[=\# 3(66)]$ is the main litchi cultivar in Taiwan and the selection Sah Keng (50) is apparently its offspring (Menzel and Simpson, 1991). The other two members are offspring of Chinese cultivars that were selected in Florida (63) and Israel (2).

Group 4 includes 20 accessions, consisting of one single accession and an additional 19 accessions which are regarded as one subgroup. All are Chinese cultivars from Guandong province, or their recent descendants. Six accessions $(38,37,36,39$, $40,22)$ were introduced to the United States from Guangzhou in 1920 by Groff (PI 51471), but their identities were lost. One of these (22) was misnamed as 'Hanging Green'. In the tree they appear as two separate groups, each consisting of three accessions that are morphologically very similar.

The two single accessions 'Kim Cheng Mesa' (29) and 'Bedana' (3) of groups 3 and 4, respectively, do not appear to be clearly related to any one of the subgroups. 'Kim Cheng Mesa' (appearing in Fig. 2 between subgroups 4 and 5 of group 3) was introduced from the Chiang Rai region of north Thailand. It is considered a promising new cultivar (Goren et al., 2001), but its identity and origin remain a mystery, as its name is unknown to the litchi experts where the graftwood was collected. The second accession 'Bedana' (appearing in Fig. 2 in the upper part of group 4) was introduced from India. Its position on the tree is far removed from all other Indian cultivars.

Bootstrap resampling analysis was used as a tool to estimate the validity of the branch topology (clusters) of the dendrogram (Felsenstein, 1985). Any branch (cluster of cultivars) that appeared $>900$ times in the 1000 bootstrap replicates $(90 \%)$ can be regarded as substantiated by the analysis. The following clusters meet this criterion: 'Chakrapad'(10) with 'Emperor' (15) and 'Haak Yip' (21) with \#3 (66) ( $100 \%$ of the 1000 replicates); the two accessions of 'Shan Chi' $(54,55)(99.9 \%)$; 'Kwai May Pink' (30) with 'Bombai' (7) (99.8\%); 'Late Seedless' (35) with 'Seedless' (53) and 'Kim Cheng' (28) 
with Wai Chee (61) (99.7\%); 'Fay Zee Siu' (16) with 'Yu Her Pau' (65) (96.3\%); the latter pair with the misnamed 'Sum Yee Hong' (57) (90.9\%) and 'Hanging Green' (22) with M 26356-C (40) $(90.1 \%)$.

Three branches were strongly supported: 'Mauritius'(41) with 'HLH Maritius' (24) (89\%); 'Brewster' (8) with 'Floridian' (17) (88.2\%) and a group of seven cultivars: 'Calcutta' (9), 'Bengal' (4), 'China'(11), 'Dehra Rose'(13), 'Lal Bombai' (33), 'Nelspruit 14-1' (43) and 'Red Mclan' (48) (82.3\%).

An additional 20 branches were partly substantiated, appearing between 800 and 300 times in the 1000 replications. Those values appear in the dendrogram (Fig. 2). One must bear in mind that the dendrogram, including the substantiated branches, the strongly supported branches, the partially substantiated branches and the nonsubstantiated branches (which appeared in less than 300 replications) are the best estimate of the real genetic similarity dendrogram, based on the matrix of band sharing calculated from our ISSR data. The abundance of the "unsubstantiated" branches in the dendrogram is expected. The evolution of lychee cultivars has a history of a few thousand years, which is a very short evolutionary period compared to other systematic phylogenetic problems in natural taxa. Therefore, we cannot conclude that the unsubstantiated topology is entirely wrong, but it is possible that some cultivars are clustered differently than in the ISSR tree, which can be revealed only by comparing the trees based on other genetic markers.

To verify our results in Fig. 2, we constructed asecond dendrogram (Fig. 3), based on a different approach for measuring genetic distances. We used the method of Nei's genetic distances (Nei, 1972), which assigns equal weights to the shared presence or shared absence of a band in estimating the genetic similarity between cultivars.

The following groups and subgroups of Fig. 2 appear without a change in Fig. 3: group 1, subgroups 2-1, 2-3, 3-1, 3-4, 3-5 and group 4 except for a single accession, WB4-8-30 (62), which appears on a different branch. This occurrence of common groups and branches in both dendrograms can be regarded as supportive evidence for the validity of their clustering.

Comparing the topology of the two dendrograms, the following differences were observed in Fig. 3: 1) 'Hazipur' (23) from subgroup 2-2 of Fig. 2 appears as a single cultivar near the Mauritius group; 2) 'Hung Long' (26), 'Brewster' (8) and 'Floridian' (17) moved from subgroup 3-2 to group 2; 3) one branch from subgroup 3-3 ['Bombai' (7) and 'Kwai Mai Pink' (30)] and one branch from subgroup 3-2 ['Groff' (20) and the two accessions of 'Shan Chi' $(54,55)]$ create a new subgroup located between 'Bengal' (4) and 'Kim Cheng Mesa' (29); 4) 'WB 4-8-30' (62) moved within group 4 to another branch. Aside from these few changes in the second similarity dendrogram (Fig. 3), most of the topology shown in Fig. 2 is reinforced by its occurrence in Fig. 3.

Parentage And ISSR data. 'Kwai May Pink' (30) has been suggested to be a strain of 'Kwai May Red' (31), which is apparently the famous Chinese cultivar 'Gui Wei' (cinnamon flavor) (Watson, 1983). However, their ISSR fingerprints are very different, rendering this assumption highly unlikely. 'Kwai May Pink' may be a seedling of 'Kwai May Red', as suggested (Menzel and Simpson, 1991).

In the similarity tree (Fig. 2), a hybrid accession is frequently located at approximately equal distances from its parents. Thus, if the parents are located in the same subgroup on the dendrogram, it is plausible that their hybrid will be placed in the same subgroup.
If the parents are located in distant subgroups, the hybrid will be placed in a midway subgroup. This hybrid topology corresponds to some of the observations made by McDade (1997), which are based on morphological characters, whereas ours are based on DNA markers.

'Yellow Red' (64) was assumed to be a chance hybrid of 'Brewster' (8) and 'Mountain' (apparently 'Shan Chi' 54, 55) (Morton, 1987). Its location on the similarity tree contradicts this assumption, as it is located in group 4, whereas both its parents are located in subgroup 3-2.

'Sah Keng' (50) is reported to be a hybrid seedling of 'Haak Yip' (21) (Menzel and Simpson, 1991). Indeed, they are clustered together in subgroup 3-5. Similarly, 'Garnet' (18) is reported to be a hybrid seedling of 'Sweet Cliff' (58) (Knight, 2001) and they are clustered together in group 4.

'BD 17-70' (2) is an offspring of 'Kaimana' (27) and its male parent has been shown to be 'No Mai Chee' (44), by isozyme analysis (C. Degani, unpublished results). 'Kaimana' is located in subgroup 3-3, 'No Mai Chee' in group 4 and 'BD 17-70' is located in subgroup 3-5 at approximately equal distances from both its parents.

'BD 17-70' is the only cross for which the identity of its parents has been confirmed. For this cross we found two nonparental bands (i.e., bands that occur in the crossed progeny and not in either of its parents). This presents $6 \%$ of the total 33 opportunities for detecting such bands (i.e., cases in which both parents lack a band detected in their progeny). Nonparental bands might result from competition during PCR amplification (Goulao et al., 2001; Hallden et al., 1996). The occurrence of nonparental bands raises concern about the potential use of ISSR technique for parentage analysis, but their low frequency of occurrence suggests that this may not be a significant problem.

In conclusion, ISSR amplification was found to be a valuable method for identifying lychee cultivars. This efficient fingerprinting technique would be very useful for routine testing of the genetic identity and purity of lychee cultivars and accessions held in germplasm collections. In addition, ISSR analysis could be a powerful tool for the certification of plant material in the lychee nursery industry.

\section{Literature Cited}

Ajibade, S.R., N.F. Weeden, and S.M. Chite. 2000. Intersimple sequence repeat analysis of genetic relationships in the genus Vigna. Euphytica $111: 47-55$.

Akkaya, M.S., A.A. Bhagwat, and P.B. Cregan. 1992. Length polymorphism of simple sequence repeat DNA in soybean. Genetics 132: 1131-1139.

Aradhya, M.K., F. Zee, and R.M. Manshardt. 1995. Isozyme variation in lychee (Litchi chinensis Sonn.). Scientia Hort. 63:21-35.

Batten, D. 1984. Lychee varieties. Agfact H6. 2.7 1-15. Dept. Agr., New South Wales.

Blair, M.W., O. Panaud, and S.R. McCouch. 1999. Intersimple sequence repeat (ISSR) amplifications for analysis of microsatellite motif frequency and fingerprinting in rice. Theor. Appl. Genet. 98:780-792.

Cavaletto, C.G. 1980. Lychee, p. 469-478. In: S. Nagy and P.E. Shaw (eds.). Tropical and subtropical fruits. AVI, Westport, Conn.

Chapman, K.R. 1984. Sapindacea: Lychee, p. 179-191. In: P.E. Page (ed.). Tropical tree fruits for Australia. Queensland Dept. Primary Industries, Brisbane.

Degani, C., A. Beiles, R. El-Batsri, M. Goren, and S. Gazit. 1995. Identifying lychee cultivars by isozyme analysis. J. Amer. Soc. Hort. Sci. 120:307-312.

Doyle, J.J. and J.L. Doyle. 1990. Isolation of plant DNA from fresh tissue. Focus 12:13-15. 
Fang, D.Q. and M.L. Roose. 1997. Identification of closely related citrus cultivars with intersimple sequence repeat markers. Theor. Appl. Genet. 95:408-417.

Fang, D.Q., R.R. Krueger, and M.L. Roose. 1998. Phylogenetic relationships among selected citrus germplasm accessions revealed by intersimple sequence repeat (ISSR) markers. J. Amer. Soc. Hort. Sci. 123:612-617.

Felsenstein, J. 1985. Confidence limits on phylogenies: An approach using bootstrap. Evolution 39:783-791.

Felsenstein, J. 1993. PHYLIP (Phylogeny Inference Package) version 3.5c. Distributed by the author. Dept. Genet., Univ. Wash., Seattle.

Felsenstein, J. 2001. PHYLIP (Phylogeny Inference Package) version $3.6 \alpha 2$. Distributed by the author. Dept. Genet., Univ. Wash., Seattle.

Galan-Sauco, V. and U.G. Menini. 1989. Litchi cultivation. FAO Plant Prod. Protection Paper 83.

Gazit, S. and M. Goren. 1997. The growth of lychee in China (in Hebrew). Alon Hanotea 51:86-89.

Gilbert, J.E., R.V. Lewis, M.J. Wilkinson, and P.D.S. Caligari. 1999. Developing an appropriate strategy to assess genetic variability in plant germplasm collections. Theor. Appl. Genet. 98:1125-1131.

Goren, M., E. Tomer, and S. Gazit. 2001. Litchi cultivars in Israel, p. 129-133. Proc. 1st Intl. Symp. Litchi and Longan, Guangzhou, China.

Groff, G.W. 1921. The lychee and lungan. Orange Judd, New York.

Groff, G.W. 1948. Additional notes upon the history of the Brewster lychee. Proc. Fla. State Hort. Soc. 64:285-289.

Goulao, L., L. Monte-Corvo, and C.M. Oliveira. 2001. Phenetic characterization of plum cultivars by high multiplex ratio markers: Amplified fragment length polymorphisms and intersimple sequence repeats. J. Amer Soc. Hort. Sci. 126:72-77.

Hallden, C.M., M. Hansen, N.O. Nilsson, A. Hjerdin, and T. Sall. 1996. Competition as a source of errors in RAPD analysis. Theor. Appl. Genet. 93:1185-1192.

Hamilton, R.A. and W. Yee. 1970. Lychee cultivars in Hawaii. Proc. Fla. State Hort. Soc. 83:322-325.

Knight, Jr., R.J. 1980. Origin and world importance of tropical and subtropical fruit crops, p. 1-120. In: S. Nagy and P.E. Shaw (eds.). Tropical and subtropical fruits. AVI, Westport, Conn.

Knight, Jr., R.J. 2001. The lychee's history and current status in Florida, p. 41-44. In: Proceedings of the First International Symposium on Litchi and Longan, Guangzhou, China.

Lagercrantz, U., H. Ellegren, and L. Andersson, 1993. The abundance of various polymorphic microsatellite motifs differs between plants and vertebrates. Nucl. Acids Res. 21:1111-1115.

Lanham, P.G. and R.M. Brennan. 1998. Characterization of the genetic resources of red currant (Ribes rubrum: subg. Ribesia) using anchored microsatellite markers. Theor. Appl. Genet. 96:917-921.

Maity, S.C. and S.K. Mitra. 1990. Litchi,p.420-468. In:T.K. Bose and S.K. Mitra (eds.). Fruits: Tropical and subtropical. Naya Prokash, India.

Martin, J.P. and M.D. Sanchez-Yelamo. 2000. Genetic relationships among species of the genus Diplotaxis (Brassicaceae) using intersimple repeat markers. Theor. Appl. Genet. 101:1234-1241.

McDade,L.A. 1997. Hybrids and phylogenetic systematic III. Comparison with distance methods. Syst. Bot. 22:669-683.

Menzel, C.M. and D.R. Simpson. 1990. Performance and improvement of lychee cultivars: A review. Fruit Var. J. 44:197-215.

Menzel, C.M. and D.R. Simpson. 1991. Adescription of lychee cultivars. Fruit Var. J. 45:45-56

Moreno, S., P. Martin, and J.M. Ortiz. 1998. Intersimple sequence re- peats PCR for characterization of closely related grapevine germplasm. Euphytica 101:117-125.

Morton, J.F. 1987. Fruits of warm climates. Creative Resource Systems Inc., Winterville, N.C.

Nei, M. 1972. Genetic distance between populations. Amer. Naturalist 106:283-298.

Nei, M. and W.H. Li. 1979. Mathematical model for studying genetic variation in terms of restriction endonucleases. Proc. Natl. Acad. Sci. USA 76:5269-5273.

Nielsen, G. 1985. The use of isozymes as probes to identify and label plant varieties and cultivars, p. 1-32. In: M.C. Ratazzi, J.G. Scandalios and G.S. Whitt (eds.). Isozymes: Current topics in biological and medical research. vol. 12. Alan R. Liss, Inc. New York.

Oppenheimer, C. 1947. The acclimatisation of new tropical and subtropical fruit trees in Palestine. Agr. Res. Sta., Rehovot, Bul. 44.

Pandey, R.M. and H.C. Sharma. 1989. The Litchi. Indian Council Agr. Res., New Delhi.

Pomology Research Institute, Guangdong Academy of Agricultural Science. 1985. An album of Guangdong litchi varieties in full color. Pomol. Res. Inst., Guangdong Acad. Agr. Sci., China.

Pomology Research Institute, Fujian Academy of Agricultural Science. 1990. An album of Fujian litchi varieties in full color. Pomol. Res. Inst., Fujian Acad. Agr. Sci., China.

Prevost, A. and M.J. Wilkinson. 1999. A new system of comparing PCR primers applied to ISSR fingerprinting of potato cultivars. Theor. Appl. Genet. 98:107-112.

Rowland, L.J. and B. Nguyen. 1993. Use of PEG for purification of DNA from leaf tissue of woody plants. BioTechniques 14:735-736.

Saitou, N. and M. Nei. 1987. The neighbor-joining method: a new method for reconstructing phylogenetic trees. Mol. Biol. Evol. 4:406-425.

Sambrook, J., E.F. Fritsch, and T. Maniatis. 1989. Molecular cloning: A laboratory manual. 2nd ed. Cold Spring Harbor Lab., Cold Spring Harbor, N.Y.

Singh, L.B. and U.P. Singh. 1954. The Litchi. Superintendent, Printing and Stationery, Uttar Pradesh, India.

Storey, W.B. 1973. The lychee. Calif. Avocado Soc. Yrbk. 56:75-86.

Subhadrabandhu, S. 1990. Lychee and longan cultivation in Thailand. Rumthai Publication Bangkok, Thailand.

Tautz, D. and M. Renz. 1984. Simple sequences are ubiquitous repetitive components of eukaryotic genomes. Nucl. Acids Res. 12: 4127-4138.

Wang, Z., J.L. Weber, G. Zhong, and S.D. Tanksley. 1994. Survey of plant short random DNA repeats. Theor. Appl. Genet. 88:1-6.

Watson, B.J. 1983. Lychee-cultivar names. Queensland Dept. Primary Ind. Farm note F36.

Weir, B.S. 1996. Genetic data analysis II. Sinauer Assoc., Inc. Publ., Sunderland, Mass.

Winston, E.C. and P.J. O'Farrell. 1993. Evaluation of lychee (Litchi chinensis Sonn.) cultivars on the Atherton Tableland of North Queensland. Fruit Var. J. 47:83-91.

Zee, F.T.P., H.T. Chan, Jr., and C. Yen. 1998. Lychee, longan, rambutan and pulasan, p. 290-335. In: P.E. Shaw, H.T. Chan, and S. Nagy (eds.). Tropical and subtropical fruits. AgScience, Inc., Fla.

Zhang, Z., P. Yuan, B. Wang, Y. Qiu, and J. Li. 1997. Litchi pictorial narration of cultivation. Z. Zhang (ed.). Pomol. Res. Inst., Guangdong Acad. Agr. Sci., China.

Zietkiewicz, E.,A. Rafalski, and D. Labuda. 1994. Genome fingerprinting by simple sequence repeat (SSR)-anchored polymerase chain reaction amplification. Genomics 20:176-183. 